\title{
Geochemical changes during metamorphic devolatilization of metasedimentary rocks: a systematic summary
}

\author{
ALEKSANDR SASHA STEPANOV \\ China University of Geosciences, Wuhan
}

Presenting Author: aleksandr@cug.edu.cn

Redistribution of elements by fluids produced by the metamorphic devolatilization (MDV) of sedimentary rocks is one of the major processes responsible for the differentiation of the Earth and the principal source of fluids that can form ore deposits. Comparison of compositions of rocks with similar original composition (protolith) with increasing metamorphic grades is the principal method of observation and quantification of the mass transfer caused by the loss of fluids. A systematic survey of published studies demonstrates that the geochemical changes caused by the MDV are different in different complexes. Some elements are depleted in almost all complexes, whereas others are affected only in exceptional cases. The major elements, and the majority of lithophile and siderophile elements are not depleted by MDV. Mercury is the first element to be lost from sediments at conditions of sub-greenschist metamorphism, which may coincide with the loss of $\mathrm{Cd}$. Arsenic depletion is almost universal in metamorphic rocks, and is correlated with the decomposition or recrystallisation of sedimentary pyrite during greenschist facies metamorphism, where it can occur at similar temperatures both in regional metamorphic rocks and in subduction zone metamorphism. Gold, $\mathrm{Sb}, \mathrm{Ag}$, and $\mathrm{W}$ depletion are documented to coincide with As loss in regional metamorphic complexes. Chlorine can be extracted by the MDV in some metamorphic sequences, whereas $\mathrm{F}$ is conserved. The majority of lithophile elements show conservative behaviour during MDV including REE, HFSE, and LILE, with the exceptions of Cs, N, U, and B in some complexes, where the depletion in some cases is associated with dehydration and in others possibly with the beginning of anatexis. MDV has the potential to be an efficient and powerful mechanism for the concentration of dispersed elements into ore-grade mineralisation. The connection between devolatilization and the origin of orogenic gold deposits is the most established, and some other deposit types are likely related to specific types of metamorphic fluids. 